\title{
ORIGINAL ARTICLE Low-density lipoprotein receptor gene transfer in hypercholesterolemic mice improves cardiac function after myocardial infarction
}

\author{
E Van Craeyveld, F Jacobs, SC Gordts and B De Geest
}

\begin{abstract}
Left ventricular (LV) function post-myocardial infarction (MI) is adversely influenced by hypercholesterolemia independent of the severity of coronary atherosclerosis. The objective of this study was to evaluate whether lipid lowering by adenoviral lowdensity lipoprotein (LDL) receptor (AdLDLr) gene transfer in C57BL/6 LDL receptor (LDLr)-deficient mice beneficially affects ventricular remodeling and cardiac function post-MI independent of effects on the coronary circulation. AdLDLr transfer reduced plasma cholesterol by $77 \%(P<0.0001)$. Survival 28 days post-MI was higher in AdLDLr-treated mice $(95 \%)$ compared with control mice $(80 \%)(P<0.05)$ (hazard ratio for mortality $0.26,95 \%$ confidence interval $0.11-0.84)$. Infarct size was not significantly different at day 1 and day 7 but was reduced by $18 \%(P<0.05)$ at day 28 in AdLDLr MI mice compared with control MI mice. Cardiomyocyte hypertrophy and interstitial fibrosis were reduced and neovascularization was increased in AdLDLr MI mice. LDLr gene transfer had beneficial effects on endothelial progenitor cell (EPC) number and ex vivo EPC function. LV contractility and relaxation were better preserved in AdLDLr MI mice compared with control MI mice. In conclusion, lipid lowering in hypercholesterolemic mice exerts direct cardioprotective effects resulting in enhanced survival, reduced infarct size, decreased ventricular remodeling and better cardiac function.
\end{abstract}

Gene Therapy (2012) 19, 860-871; doi:10.1038/gt.2011.147; published online 6 October 2011

Keywords: low-density lipoprotein receptor gene transfer; hypercholesterolemia; lipid lowering; myocardial infarction; cardiac function; remodeling

\section{INTRODUCTION}

The loss of myocardial tissue following acute myocardial infarction (MI) results in a sudden increase in loading conditions. This induces ventricular remodeling, which involves both the infarcted border zone and remote non-infarcted myocardium. ${ }^{1}$ Impairment of cardiac function as a result of ventricular remodeling post-acute MI may lead to the development of heart failure. Ischemic heart disease is the main cause of heart failure. ${ }^{2}$

Hypercholesterolemia is a well-established risk factor for the development of coronary atherosclerosis. However, whether hypercholesterolemia modulates myocardial infarct size and ventricular remodeling independent of its effects on the coronary circulation has not been investigated till now. In patients with a first MI, hypercholesterolemia is associated with a more pronounced deterioration of the left ventricular (LV) function independent of the severity of coronary atherosclerosis. ${ }^{3}$ In addition, lipidlowering therapy before $\mathrm{MI}$ is associated with reduced myocardial necrosis as evaluated by peak creatine kinase-MB activity. ${ }^{4}$ However, the cardioprotective effects of statins, the most widely used hypolipidemic drugs, may be indirect via its effects on endothelial function and on myocardial perfusion post-MI. ${ }^{5}$ In addition, these cardioprotective effects of statins are at least partly independent of cholesterol lowering. In a similar way, statins limit myocardial infarct size in normocholesterolemic mice subjected to ischemia and reperfusion injury via enhanced nitric oxide production. ${ }^{6,7}$ Taken together, whether cholesterol levels have direct effects on ventricular remodeling post-MI, remains un-established.
We have previously shown that myocardial-free cholesterol levels are significantly elevated in hypercholesterolemic lowdensity lipoprotein (LDL) receptor (LDLr)-deficient mice and that this is reversed by lipid-lowering gene transfer. ${ }^{8}$ Cholesterol has important structural and functional roles in membranes, particularly in the plasma membrane. An altered membrane cholesterol content changes the physical properties of the membrane ${ }^{9}$ and may affect the function of pumps, ion channels and enzymes. An increased cholesterol content in the lipid bilayer of the cardiac sarcolemmal membrane of isolated cardiomyocytes decreases cytosolic calcium levels and impairs ex vivo contractility and relaxation. ${ }^{10-12}$ Therefore, a biochemical and physiological rationale exists for the hypothesis that cholesterol exerts direct effects on the myocardium and may directly influence ventricular remodeling post-MI.

The goal of this study was to investigate whether selective lipid lowering induced by LDL-lowering gene transfer in hyperlipidemic C57BL/6 $\mathrm{LDLr}^{-/}$mice affects ventricular remodeling post-MI via direct effects on the myocardium. In order to exclude indirect effects of plasma cholesterol on ventricular remodeling via modulation of coronary perfusion, a model of permanent ligation of the left anterior descending coronary artery was applied. The use of LDL-lowering gene transfer precludes non-lipid effects that may occur with statin therapy. Our results show that LDLr gene transfer in hypercholesterolemic mice before MI exerts direct cardioprotective effects resulting in enhanced survival, reduced infarct size, attenuated ventricular remodeling and improved cardiac function. 


\section{RESULTS}

AdLDLr gene transfer persistently lowers plasma lipoprotein levels in female $\mathrm{LDLr}^{-1-}$ mice on a high-cholesterol, high-fat diet

To induce pathophysiologically relevant levels of hypercholesterolemia, female C57BL/6 $\mathrm{LDLr}^{-1-}$ mice were fed a diet containing $0.2 \%(\mathrm{w} / \mathrm{w})$ cholesterol and $10 \%(\mathrm{v} / \mathrm{w})$ coconut oil. Three weeks after start of the diet, mice were treated with the LDLr-expressing vector adenoviral LDLr (AdLDLr). Control mice were injected with the control vector Adnull or with saline buffer. Figures $1 a$ and $b$ show the time course of total, non-high-density lipoprotein (HDL) and HDL plasma cholesterol levels in control mice and AdLDLr-treated mice, respectively. Average cholesterol levels in the different lipoprotein classes during the final 4 weeks of the experiment are presented in Table 1. Average total plasma cholesterol levels were reduced by $77 \%(P<0.0001)$ following AdLDLr gene transfer compared with control mice, which was mainly due to a lowering of non-HDL cholesterol levels by $86 \%$ $(P<0.0001)$ (Table 1). The reduced non-HDL cholesterol values reflect a decrease in $\mathrm{LDL}$, intermediate density lipoproteins and very low density lipoproteins cholesterol levels by $80 \%$ $(P<0.0001)$, 90\% $(P<0.0001)$ and $86 \%(P<0.0001)$, respectively (Table 1). HDL cholesterol levels were reduced by $27 \%(P<0.0001)$ compared with control mice (Table 1). The cholesterol-lowering effect of AdLDLr was significantly more pronounced than the cholesterol-lowering effect of a previously described vector ${ }^{1}$ expressing the LDLr under control of a $1.5 \mathrm{~kb}$ human $\alpha_{1}$-antitrypsin promoter and four copies of the human apo $E$ enhancer (Supplementary Figure 1).

Lipid lowering improves survival after $\mathrm{MI}$ in hypercholesterolemic $\mathrm{LDLr}^{-1-}$ mice

MI was induced 2 weeks after gene transfer or saline injection by permanent ligation of the left anterior descending coronary artery. To investigate whether AdLDLr gene transfer affects survival after MI, Kaplan-Meier survival curves were compared by log-rank test (Figure 2). Survival 28 days post-MI was significantly higher in AdLDLr-treated mice (95\%; 52 mice survived of 55) compared with control mice $(80 \% ; 49$ mice survived of 61$)(P<0.05)$ (hazard ratio for mortality $0.26,95 \%$ confidence interval $0.11-0.84)$.

AdLDLr gene transfer in hypercholesterolemic mice reduces infarct size 28 days post-Ml

Twenty-four hours after left anterior descending coronary artery (LAD) ligation, no significant differences in ischemic risk area (expressed as percentage of LV wall area; $67 \pm 2.0 \%$. versus $60 \pm 2.8 \% ; P=\mathrm{NS}$ ) and infarct size (expressed as percentage of ischemic risk area; $97 \pm 1.1 \%$ versus $96 \pm 1.4 \% ; P=\mathrm{NS})$ were observed between control $(n=6)$ and $\operatorname{AdLDLr}(n=7)$ treated mice. Seven days post-Ml, infarct size (expressed as midline infarct length normalized to midline LV circumference) was similar in control and AdLDLr-treated mice (Figure 3a). In contrast to control mice, infarct size in AdLDLr-treated mice decreased substantially between day 7 and day 28 after MI $(P<0.05)$ (Figure 3a). As a result, infarct size 28 days post-Ml was $18 \%(P<0.05)$ smaller in the AdLDLr-treated group compared with the control group (Figure 3a). Representative Sirius red-stained cross-sections of non-infarcted control hearts and infarct hearts at day 7 and day 28 post-MI of control and AdLDLr-treated mice are shown in Figure 4.

A smaller infarct size 28 days post-MI may reflect a more pronounced infarct contraction or LV chamber dilatation. Therefore, a detailed morphometric analysis was performed to determine infarct area, LV remote muscle area and LV cavity area. Morphometric data of LV remodeling in the different groups are summarized in Table 2. No difference of absolute cross-sectional infarct area was observed at day 7 after MI between the AdLDLr group and the control group (Figure $3 \mathrm{~b}$, Table 2). Infarct area decreased in both groups between day 7 and day 28 , indicating

Table 1. Average total, non-HDL, HDL, VLDL, IDL, LDL and $\mathrm{HDL}$ cholesterol levels $\left(\mathrm{mg} \mathrm{dl}^{-1}\right)$ in plasma of diet $(0.2 \%$ cholesterol, $10 \%$ coconut oil)-fed female C57BL/6 $\mathrm{LDLr}^{-1-}$ mice for the 4-week follow-up period starting 2 weeks after injection with saline or $5 \times 10^{10}$ particles of Adnull (controls) or after injection with $5 \times 10^{10}$ particles of AdLDLr

\begin{tabular}{lrc}
\hline & Controls & AdLDLr \\
\hline Total & $360 \pm 7.4$ & $82 \pm 4.8^{*}$ \\
Non-HDL & $300 \pm 7.8$ & $42 \pm 3.6^{*}$ \\
VLDL & $68 \pm 6.1$ & $9.8 \pm 1.4^{*}$ \\
IDL & $140 \pm 3.0$ & $14 \pm 1.2^{*}$ \\
LDL & $97 \pm 3.3$ & $19 \pm 1.8^{*}$ \\
HDL & $55 \pm 1.6$ & $40 \pm 1.7^{*}$ \\
\hline
\end{tabular}

Abbreviations: AdLDLr, adenoviral LDLr; HDL, high-density lipoprotein; IDL, intermediate density lipoproteins; LDL, low-density lipoprotein; LDLr, LDL receptor; VLDL, very low density lipoproteins. ${ }^{*} P<0.0001$ versus controls. Data are expressed as means \pm s.e.m. Average values were obtained by dividing the area under the curve by the time of follow-up $(n=10$ for each condition).
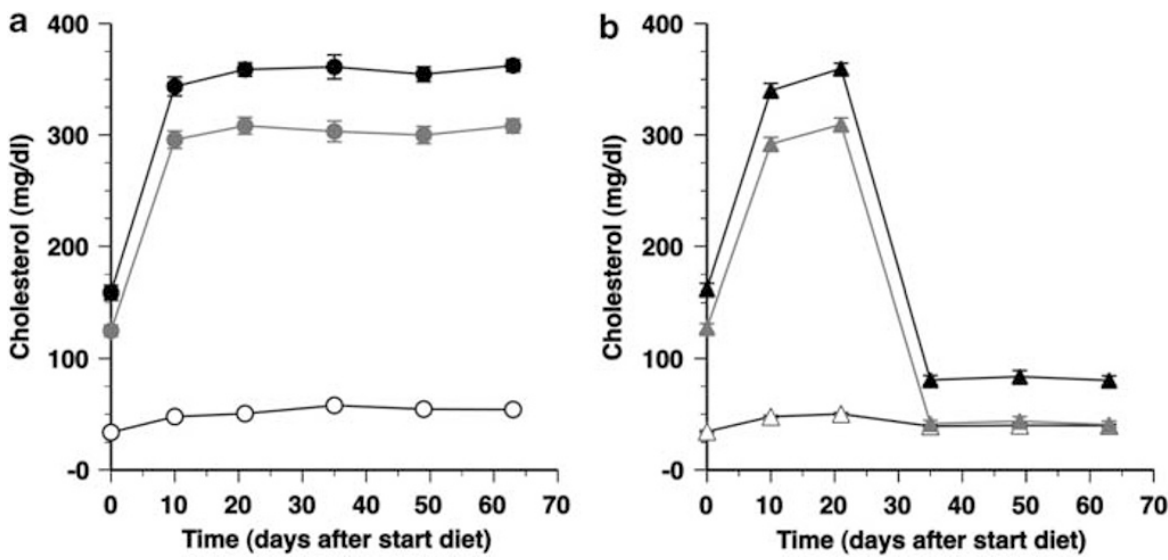

Figure 1. Time course of total plasma cholesterol levels (black closed circle, black closed triangle), non-HDL plasma cholesterol levels (gray closed circle, gray closed triangle) and HDL plasma cholesterol levels (open circle, open triangle) (mg dl ${ }^{-1}$ ) in female $\mathrm{C}^{2} \mathrm{BL} / 6 \mathrm{LDLr}^{-/-} \mathrm{mice}$ of the control group (a) and AdLDLr-treated group (b). The day 0 time-point corresponds to the start of the $0.2 \%$ cholesterol and $10 \%$ coconut oil diet, which was initiated 21 days before saline injection or before gene transfer with $5 \times 10^{10}$ particles of Adnull or AdLDLr. Data are shown as means \pm s.e.m. $(n=10$ for each time-point). 
infarct contraction (Figure 3b, Table 2). However, the more pronounced infarct contraction in the AdLDLr group resulted in a $25 \%(P<0.01)$ smaller infarct area compared with control mice at day 28 after MI (Figure 3b, Table 2). Compared with non-infarcted hearts, LV remote muscle area was significantly decreased at day 7 reflecting muscle loss caused by the ligation of the LAD. Between 7 and 28 days after $\mathrm{MI}$, a significant increase in LV remote muscle area was observed in both $\mathrm{Ml}$ groups. However, 28 days after $\mathrm{MI}$, LV remote muscle area was significantly larger in AdLDLr-treated MI mice compared with control MI mice $(P<0.05)$ (Table 2$)$. LV cavity area increased significantly following $\mathrm{Ml}$, but did not differ between AdLDLr-treated and control mice at day 7 or day 28 postMI. The thinning index decreased significantly between day 7 and day 28 after Ml, but did not differ between both Ml groups (Table 2). The expansion index increased significantly between day 7 and day 28 post-MI, but was similar between both MI groups at both time points (Table 2).

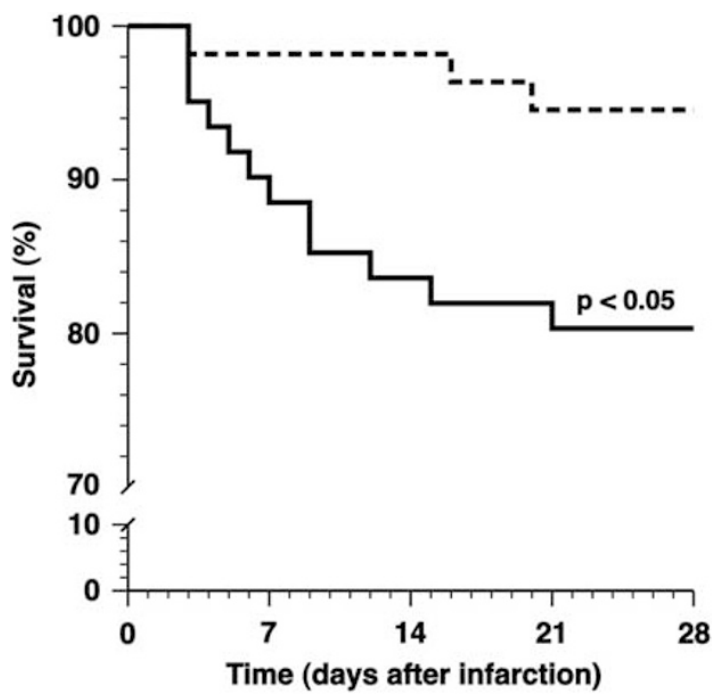

Figure 2. Kaplan-Meier curves showing survival of control (full line) and AdLDLr-treated (dashed line) female C57BL/6 $\mathrm{LDLr}^{-/-}$mice after MI. The 0 day time-point corresponds to the induction of $\mathrm{Ml}$, which was performed 14 days after saline injection or after gene transfer with Adnull or AdLDLr. Analysis of survival was performed by the Kaplan-Meier method, and between-group difference in survival was tested by the log-rank test with Prism 4 (GraphPad Software).
LDLr gene transfer in hypercholesterolemic mice reduces inflammation in the remote LV myocardium and counteracts $\mathrm{LV}$ remodeling after $\mathrm{MI}$

MI resulted in a significant increase in inflammatory cells in the remote LV myocardium at day 7 after MI (Table 3, Figure 5). At that time point, CD45-positive leukocyte infiltration was $26 \%(P<0.05)$ lower in AdLDLr gene transfer MI mice compared with control MI mice. Twenty-eight days after MI, leukocyte density in the remote LV myocardium was normalized to baseline levels in both groups.

One of the major features of ventricular remodeling after $\mathrm{MI}$ is cardiomyocyte hypertrophy. Cardiomyocyte cross-sectional area was $13 \%(P<0.05)$ and $15 \%(P<0.01)$ smaller at day 7 and day 28 respectively, in AdLDLr-treated MI mice compared with control MI mice (Table 3). Accordingly, cardiomyocyte density was significantly higher in AdLDLr-treated MI mice than in control MI mice 7 days $(P<0.01)$ and 28 days $(P<0.05)$ post-Ml. AdLDLr gene transfer also significantly increased capillary density in the remote LV myocardium at both time points following $\mathrm{MI}(P<0.05)$ (Table 3). Mismatch between cardiomyocyte size and vascularity may contribute to the transition from cardiac hypertrophy to heart failure. ${ }^{13}$ Relative vascularity, calculated as the ratio of capillary density to cardiomyocyte density divided by the cardiomyocyte cross-sectional area $\left(\mu \mathrm{m}^{2}\right)$, was 1.2 -fold $(P<0.05)$ and 1.2 -fold $(P<0.01)$ higher in AdLDLr gene transfer MI mice compared with control MI mice 7 days and 28 days after MI, respectively (Table 3 ). Representative photomicrographs of laminin-stained cardiomyocytes, CD31-positive capillaries and laminin-CD31 double staining are shown for the different groups in Figure 5.

The level of interstitial fibrosis was determined on Sirius redstained sections (Figure 5). Deposition of interstitial collagen was significantly increased in both control and AdLDLr mice following MI (Table 3). However, interstitial fibrosis was significantly more pronounced in control MI mice compared with AdLDLr-treated MI mice 7 days $(P<0.01)$ and 28 days $(P<0.05)$ post-Ml (Table 3$)$.

LDLr gene transfer increases capillary density in the infarct area of hypercholesterolemic mice 28 days post-MI

Table 4 summarizes the histological data of the infarct area for control and AdLDLr-treated mice 7 days and 28 days after MI. Representative pictures of (immuno)histochemical stainings are shown in Figure 6. Gene transfer with AdLDLr resulted in a 1.3-fold $(P<0.01)$ higher density of CD31-positive capillaries in the infarct area compared with control mice at day 28 after MI (Table 4). No difference in capillary density was observed 7 days post-MI. In the infarct border zone, capillary density was similar between a

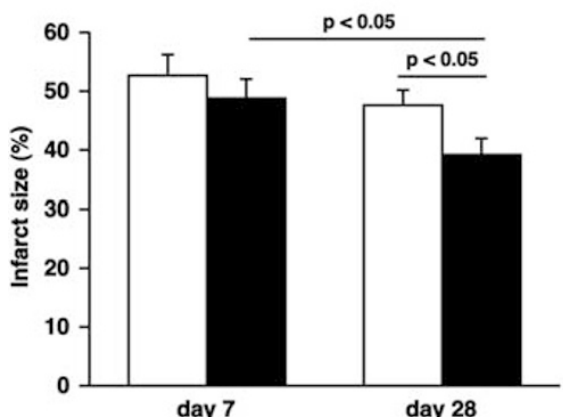

b

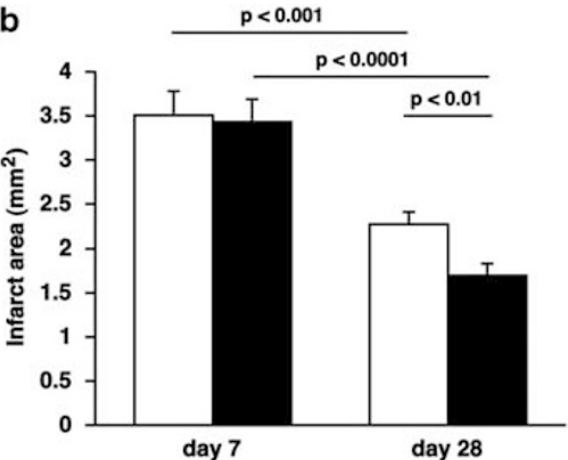

Figure 3. (a) Bar graph showing infarct size of control (open bars) and AdLDLr-treated (closed bars) C57BL/6 LDLr ${ }^{-1-}$ mice 7 days and 28 days after permanent ligation of the left anterior descending coronary artery. Infarct size (\%) was calculated by dividing the sum of midline infarct lengths from all sections by the sum of midline LV circumferences from all sections and multiplying by 100. (b) Bar graph showing infarct area of control (open bars) and AdLDLr-treated (closed bars) C57BL/6 LDLr ${ }^{-1-}$ mice 7 days and 28 after MI. Data are expressed as means \pm s.e.m. $(n=15-22$ per group). 


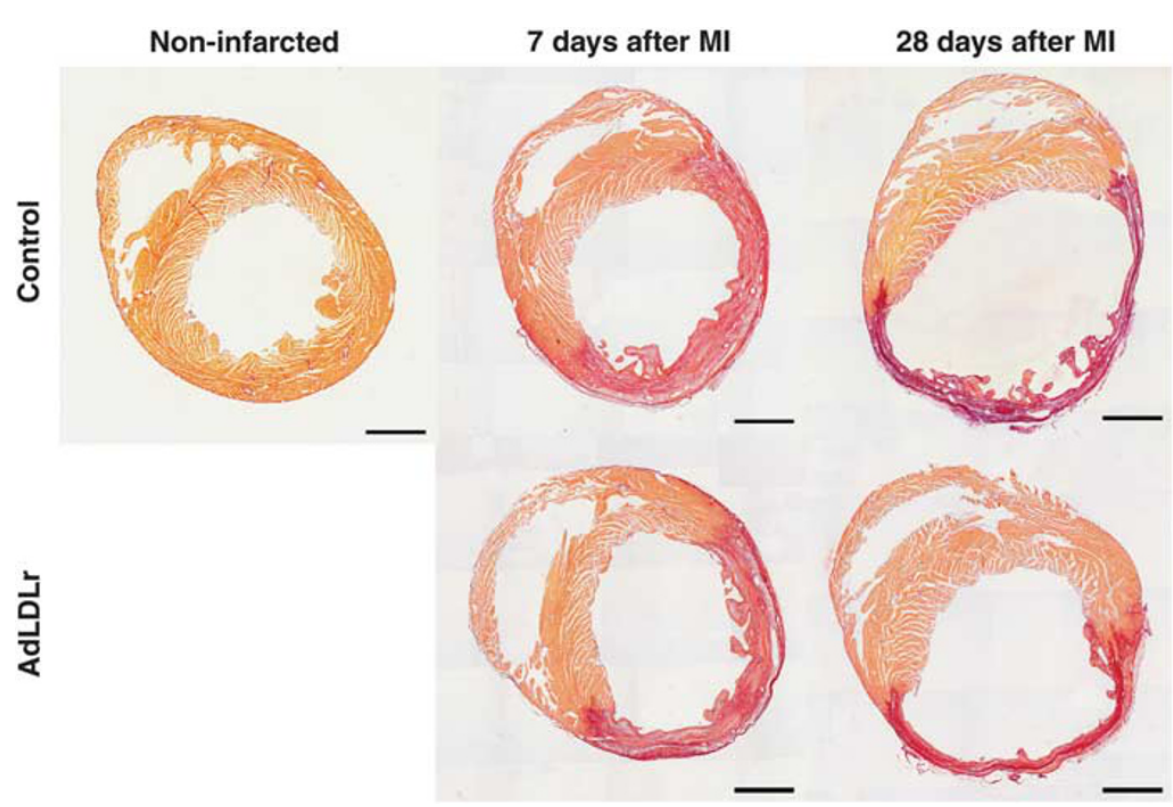

Figure 4. Representative Sirius red-stained cross-sections of non-infarcted control hearts and 7-day and 28-day infarct hearts of control and AdLDLr-treated female C57BL/6 $\mathrm{LDLr}^{-1-}$ mice. Morphometric analysis was performed on tissue sections of 4 separate regions using Axiovision 4.6 software (Zeiss). Scale bar represents $1 \mathrm{~mm}$.

Table 2. Morphometric analysis of LV remodeling in non-infarcted control C57BL/6 $\mathrm{LDLr}^{-1-}$ mice and in control and AdLDLr-treated female $\mathrm{C} 57 \mathrm{BL} / 6 \mathrm{LDLr}^{-1-}$ mice 7 days and 28 days after $\mathrm{Ml}$

\begin{tabular}{|c|c|c|c|c|c|}
\hline & \multirow{2}{*}{$\begin{array}{l}\text { Non-infarcted } \\
\text { Control }(\mathrm{n}=11)\end{array}$} & \multicolumn{2}{|c|}{7 Days after $M I$} & \multicolumn{2}{|c|}{28 Days after $M I$} \\
\hline & & Control $(\mathrm{n}=15)$ & $\operatorname{AdLDLr}(\mathrm{n}=15)$ & Control $(n=21)$ & $\operatorname{AdLDLr}(\mathrm{n}=22)$ \\
\hline LV remote muscle area $\left(\mathrm{mm}^{2}\right)$ & $9.4 \pm 0.26$ & $6.6 \pm 0.46^{\S \S \S \S}$ & $6.1 \pm 0.33^{\S \S \S \S}$ & 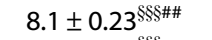 & $8.9 \pm 0.23^{* \# \# \# \#}$ \\
\hline LV cavity area $\left(\mathrm{mm}^{2}\right)$ & $3.9 \pm 0.42$ & $6.1 \pm 0.29^{\S \S}$ & $6.4 \pm 0.33^{8 \$ 8 \S}$ & $7.4 \pm 0.66^{\S \S \S}$ & $8.0 \pm 0.71^{\$ \S \S}$ \\
\hline LV cavity area/whole LV area & $0.29 \pm 0.026$ & $0.38 \pm 0.016^{\S \S}$ & $0.40 \pm 0.012^{\S \S}$ & $0.41 \pm 0.020^{\S \S}$ & $0.41 \pm 0.024^{\S \S}$ \\
\hline
\end{tabular}

Table 3. Histological analysis of remote LV myocardium in non-infarcted control C57BL/6 LDLr ${ }^{-1-}$ mice and in control and AdLDLr-treated female C57BL/6 $\mathrm{LDLr}^{-1-}$ mice 7 days and 28 days after MI

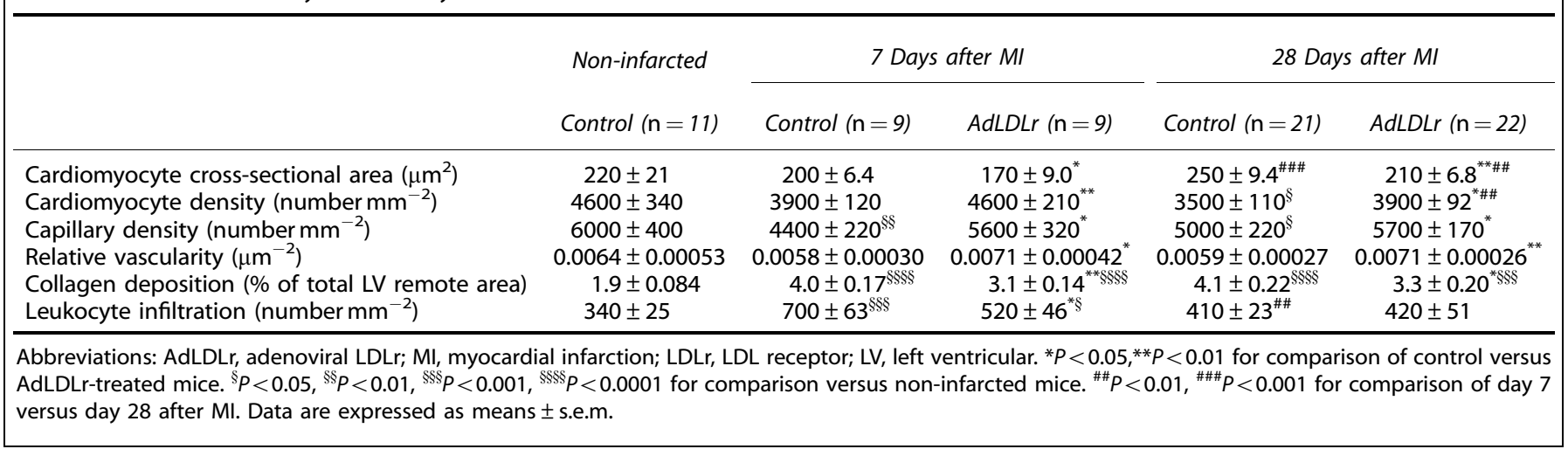

control and AdLDLr-treated mice at both time points after MI (data not shown). Collagen deposition increased significantly between day 7 and day 28 after Ml, reflecting enhanced infarct healing over time, but did not differ between both groups (Table 4). Infiltration of CD45-positive leukocytes and smooth muscle cell $\alpha$-actinpositive myofibroblasts in the infarct area decreased significantly during the follow-up period after $\mathrm{Ml}$, and was similar in both groups (Table 4). 


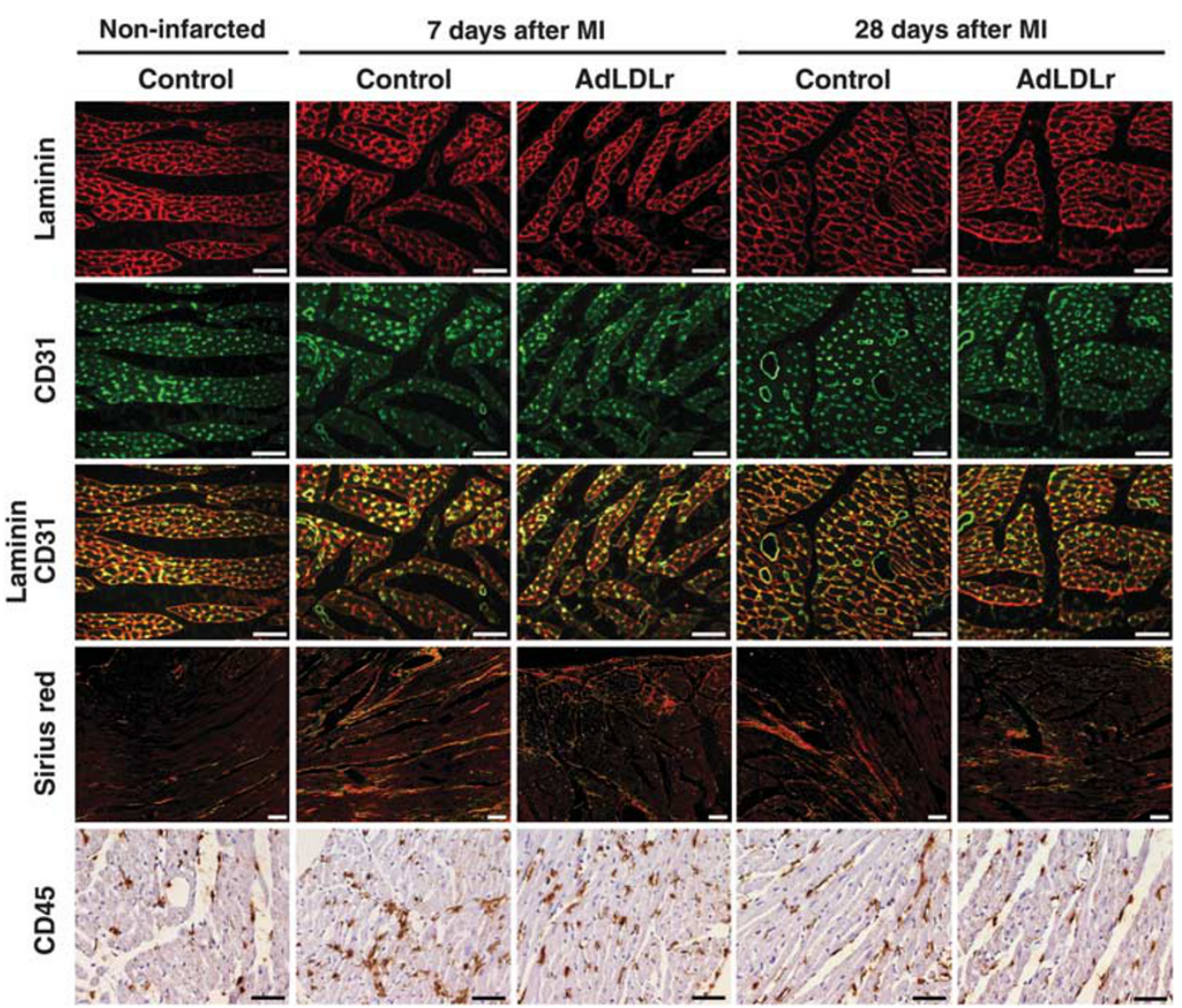

Figure 5. (Immuno)histochemical analysis of LV remodeling in remote myocardium of non-infarcted control C57BL/6 LDLr ${ }^{-1-}$ mice and control and AdLDLr-treated female C57BL/6 $\mathrm{LDLr}^{-1-}$ mice 7 days and 28 days after Ml. Representative photomicrographs show lamininstained cardiomyocytes, CD31-positive capillaries and laminin-CD31 double staining, Sirius red-stained interstitial collagen viewed under polarized light, and CD45-positive leukocytes. Scale bar represents $50 \mu \mathrm{m}$.

Table 4. Histological analysis of infarct area in control and AdLDLr-treated female C57BL/6 $\mathrm{LDLr}^{-/-}$mice 7 days and 28 days after MI

\begin{tabular}{|c|c|c|c|c|}
\hline & Control $(\mathrm{n}=15)$ & $\operatorname{AdLDLr}(\mathrm{n}=15)$ & Control $(\mathrm{n}=21)$ & $\operatorname{AdLDLr}(\mathrm{n}=22)$ \\
\hline Collagen deposition (\% of infarct area) & $29 \pm 1.4$ & $28 \pm 1.9$ & $50 \pm 1.9^{\# \# \# \#}$ & $49 \pm 1.7^{\# \# \# \#}$ \\
\hline Leukocyte infiltration (number $\mathrm{mm}^{-2}$ ) & $4400 \pm 260$ & $3800 \pm 230$ & $1200 \pm 110^{\# \# \# \#}$ & $1100 \pm 92^{\# \# \# \#}$ \\
\hline Myofibroblast infiltration (\% of infarct area) & $4.4 \pm 0.51$ & $4.3 \pm 0.37$ & $1.2 \pm 0.17^{\# \# \# \#}$ & $0.80 \pm 0.094^{\# \# \# \#}$ \\
\hline
\end{tabular}

LDLr gene transfer has beneficial effects on endothelial progenitor cell (EPC) number and ex vivo EPC function but not on EPC incorporation-AdLDLr gene transfer has beneficial effects on neovascularization following MI. EPCs may enhance neovascularization via paracrine effects and/or increased EPC incorporation. Therefore, we investigated the effect of AdLDLr gene transfer on EPC number, ex vivo EPC function and in vivo EPC incorporation. EPCs were isolated from spleens of Adnull or AdLDLr-treated C57BL/6 $\mathrm{LDLr}^{-1-}$ mice. After culture for 7 days, EPC number was analyzed by quantification of Dil-acLDL fluorescein isothiocyanateisolectin double-positive cells. The number of spleen EPCs was 2.0-fold $(P<0.05)$ higher after AdLDLr transfer $(n=5)$ than after Adnull transfer $(n=5)$ (Supplementary Figure 2A). To evaluate the effect of AdLDLr gene transfer on EPC function, EPC migration and adhesion assays were performed. The number of migrated EPCs isolated from AdLDLr-treated mice $(n=12)$ was 2.8 -fold higher
$(P<0.0001)$ compared with EPCs derived from Adnull-treated mice $(n=12)$ (Supplementary Figure 2B). The adherence to fibronectin-coated plates was 1.5 -fold $(P<0.01)$ higher for EPCs isolated from AdLDLr-injected mice $(n=6)$ than for EPCs derived from Adnull-injected mice $(n=6)$ (Supplementary Figure 2C). To quantify the incorporation of bone marrow-derived EPCs in the heart of $\mathrm{Ml}$ mice, bone marrow transplantations with bone marrow of $\mathrm{C} 57 \mathrm{BL} / 6 \mathrm{LDLr}^{-1-} \beta$-actin green fluorescent protein (GFP) mice was performed 4 weeks before the start of the diet. Supplementary Figure 3 shows that the number of CD31 GFP double-positive capillaries was not significantly higher at day 28 in the AdLDLr-treated MI group compared with the control MI group in both the infarct area (Supplementary Figure $3 \mathrm{~A}$ ) and the infarct border zone (Supplementary Figure 3B). Immunohistochemical staining for CD31 and GFP in the infarct area is shown in Supplementary Figure 4. Taken together, lipid lowering after 
7 days after MI
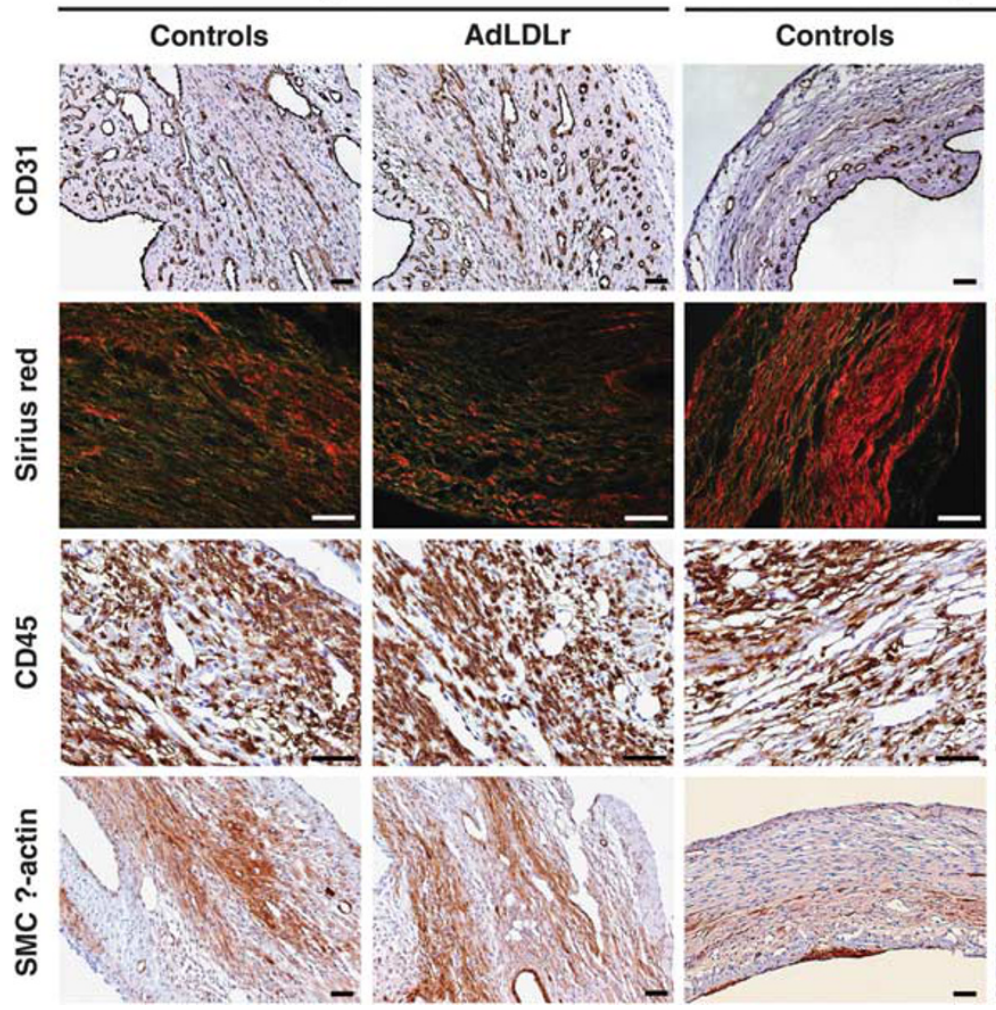

28 days after MI
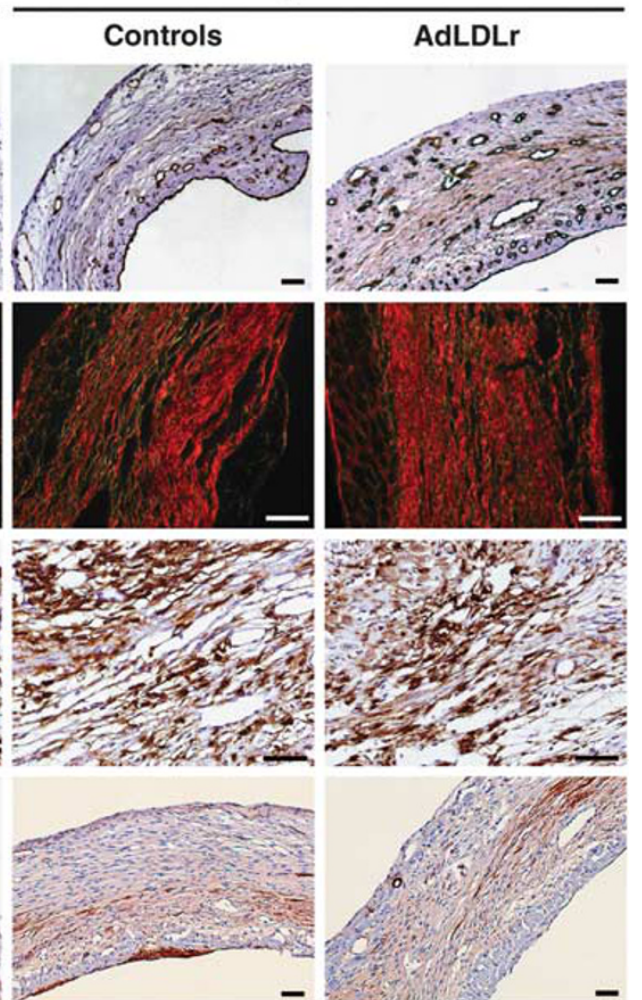

Figure 6. (Immuno)histochemical analysis of the infarct area in control and AdLDLr-treated female C57BL/6 LDLr ${ }^{-1-}$ mice 7 days and 28 days after MI. Representative photomicrographs show CD31-positive capillaries, Sirius red-stained collagen viewed under polarized light, CD45positive leukocytes and smooth muscle cell $\alpha$-actin-positive myofibroblasts. Scale bar represents $50 \mu \mathrm{m}$.

AdLDLr gene transfer increases EPC number and enhances EPC function, but does not affect EPC incorporation, suggesting that the contribution of EPCs to augmented neovascularization after AdLDLr gene transfer in vivo is restricted to paracrine effects.

LDLr gene transfer enhances cardiac function after MI in hypercholesterolemic $\mathrm{LDLr}^{-/-}$mice

Hemodynamic variables in non-infarcted sham controls and in control MI and AdLDLr MI mice at day 28 after surgery are shown in Table 5. Hemodynamic measurements in the LV demonstrated an increased peak rate of isovolumetric contraction $\left(\mathrm{dP} / \mathrm{dt}_{\text {maxi }}\right.$; $P<0.05)$ and an increased peak rate of isovolumetric relaxation $\left(\mathrm{dP} / \mathrm{dt}_{\text {min }} ; P<0.05\right)$ in AdLDLr MI mice compared with control MI mice. The LV peak systolic pressure was significantly higher in AdLDLr Ml mice than in control Ml mice $(P<0.01)$. The mean peripheral blood pressure $(P<0.01)$, peak systolic peripheral blood pressure $(P<0.05)$ and peak diastolic peripheral blood pressure $(P<0.01)$ were significantly higher in AdLDLr MI mice compared with control Ml mice and were similar to the pressure in noninfarcted mice.

Lipid lowering following LDLr gene transfer in hypercholesterolemic $\mathrm{LDLr}^{-/-}$mice alters expression of several key genes involved in ventricular remodeling post-MI

Table 6 summarizes gene expression quantifications in the remote LV myocardium of control non-infarcted mice and of control and AdLDLr-treated mice 28 days after MI.

LV mRNA expression of angiotensin II receptor type 1a (Agtr1a), a major component of the renin-angiotensin system, was significantly reduced 28 days following MI (Table 6). In AdLDLr-treated
MI mice, Agtr1a mRNA expression was 1.3 -fold $(P<0.001)$ higher compared with control MI mice.

Connective tissue growth factor (Ctgf) mRNA expression markedly increased after Ml. However, AdLDLr gene transfer MI mice showed significantly lower Ctgf mRNA expression levels compared with control MI mice (Table 6), which is consistent with the lower degree of interstitial fibrosis in the lipid-lowering MI group (Table 3).

Atrial natriuretic peptide (Nppa) mRNA expression in the remote LV of control MI mice was 10 -fold $(P<0.0001)$ higher compared with non-infarcted control mice and was similar to values in AdLDLr-treated MI mice (Table 6). The MRNA expression of brain natriuretic peptide (Nppb) also significantly increased following MI. This increase in Nppb mRNA expression was attenuated in the AdLDLr gene transfer Ml group compared with the control Ml group (1.8-fold difference; $P<0.001)$, consistent with less remodeling and improved ventricular function in the AdLDLr MI group (Table 6).

Oxidative stress may have a role in the pathophysiology of LV remodeling post-MI. Nicotinamide-adenine dinucleotide phosphate (NADPH) oxidases are major sources of reactive oxygen species production in the heart. Among the five NADPH oxidase (Nox) isoforms, Nox2 and Nox4 are expressed in cardiomyocytes. Nox2 mRNA expression was found to be 2.0 -fold $(P<0.01)$ increased after $\mathrm{Ml}$ in the control group but no significant difference was observed compared with AdLDLr-treated MI mice (Table 6). Myocardial Nox4 mRNA expression in control MI mice was 9.0 -fold $(P<0.0001)$ increased 28 days after $\mathrm{Ml}$, and was 1.9 -fold $(P<0.05)$ higher compared with values in AdLDLr-treated MI mice. Expression of the antioxidant enzymes superoxide dismutase (Sod)1, Sod2 and Sod3 was not significantly changed following $\mathrm{Ml}$ and did not differ between control Ml mice and 
Table 5. Hemodynamic parameters in control and AdLDLr-treated female $\mathrm{C} 57 \mathrm{BL} / 6 \mathrm{LDLr}^{-1-}$ mice 28 days after sham operation or $\mathrm{MI}$

\begin{tabular}{|c|c|c|c|}
\hline & \multirow{2}{*}{$\begin{array}{c}\begin{array}{c}\text { Non- } \\
\text { infarcted }\end{array} \\
\text { Control }\end{array}$} & \multicolumn{2}{|c|}{28 Days after $M I$} \\
\hline & & Control & AdLDLr $r$ \\
\hline \multicolumn{4}{|l|}{ Left ventricle } \\
\hline Number of mice & 6 & 16 & 18 \\
\hline Mean pressure $(\mathrm{mm} \mathrm{Hg})$ & $49 \pm 1.1$ & $44 \pm 2.5$ & $49 \pm 2.7$ \\
\hline Peak systolic pressure $(\mathrm{mm} \mathrm{Hg})$ & $120 \pm 2.8$ & $98 \pm 3.5^{\S \S}$ & $110 \pm 2.9^{* *}$ \\
\hline End-diastolic pressure $(\mathrm{mm} \mathrm{Hg})$ & $1.1 \pm 0.94$ & $6.3 \pm 2.0^{\S}$ & $5.6 \pm 1.7^{\S}$ \\
\hline Peak dP/dt $\max \left(\mathrm{mm} \mathrm{Hg} \mathrm{ms}^{-1}\right)$ & $15 \pm 0.76$ & $11 \pm 0.59^{\S \S}$ & $12 \pm 0.44^{* \$ S}$ \\
\hline Peak $\mathrm{dP} / \mathrm{dt}_{\min }\left(\mathrm{mm} \mathrm{Hg} \mathrm{ms}^{-1}\right)$ & $-12 \pm 1.0$ & $-7.4 \pm 0.48^{8 S \S \S}$ & $-8.7 \pm 0.32^{* \mathrm{~S} S}$ \\
\hline Tau (ms) & $4.0 \pm 0.22$ & $7.0 \pm 0.74^{\S \S \S}$ & $6.3 \pm 0.46^{6 \$ s}$ \\
\hline Heart rate (b.p.m.) & $640 \pm 21$ & $600 \pm 19$ & $600 \pm 12$ \\
\hline \multicolumn{4}{|l|}{ Aorta } \\
\hline Number of mice & 7 & 22 & 22 \\
\hline Mean pressure $(\mathrm{mm} \mathrm{Hg})$ & $94 \pm 3.0$ & $79 \pm 2.6^{\S \S}$ & $90 \pm 2.1^{* *}$ \\
\hline Peak systolic pressure $(\mathrm{mm} \mathrm{Hg})$ & $110 \pm 3.4$ & $96 \pm 2.6^{\S \S}$ & $110 \pm 2.5^{*}$ \\
\hline Peak diastolic pressure $(\mathrm{mm} \mathrm{Hg})$ & $79 \pm 3.0$ & $64 \pm 2.8^{\S \S}$ & $77 \pm 1.9^{* * *}$ \\
\hline
\end{tabular}

Abbreviations: AdLDLr, adenoviral LDLr; MI, myocardial infarction; LDLr, LDL receptor. ${ }^{*} P<0.05,{ }^{* *} P<0.01,{ }^{* * *} P<0.001$ for comparison of control versus AdLDLr-treated mice. ${ }^{\$} P<0.05,{ }^{\$ \S} P<0.01,{ }^{\$ \$ \$} P<0.001$, ${ }^{\$ \$ S \$} \$ P<0.0001$ for comparison versus non-infarcted mice. Data are expressed as means \pm s.e.m.

Table 6. Analysis of mRNA expression levels and of lipid peroxidation in the remote LV myocardium in non-infarcted control C57BL/6 $\mathrm{LDLr}^{-/-}$mice and in control and AdLDLr-treated C57BL/6 $\mathrm{LDLr}^{-1-}$ mice 28 days after $\mathrm{MI}$

\begin{tabular}{|c|c|c|c|}
\hline & \multirow{2}{*}{$\begin{array}{c}\begin{array}{c}\text { Non- } \\
\text { infarcted }\end{array} \\
\text { Control }\end{array}$} & \multicolumn{2}{|c|}{28 Days after MI } \\
\hline & & Control & AdLDLr \\
\hline \multicolumn{4}{|c|}{ Gene expression (mRNA expression normalized to Gapdh) } \\
\hline Agtr1a & $1.0 \pm 0.098$ & $0.43 \pm 0.018^{\S \S \S}$ & $0.58 \pm 0.033^{* * * \Omega S}$ \\
\hline Ctgf & $1.0 \pm 0.15$ & $9.3 \pm 1.1^{\S \S \S \S}$ & $5.2 \pm 0.96^{*} \S \S \S$ \\
\hline Nox2 & $1.0 \pm 0.12$ & $2.0 \pm 0.21^{\S \S}$ & $1.5 \pm 0.22$ \\
\hline Nox4 & $1.0 \pm 0.19$ & $9.0 \pm 1.2^{\S \S \S \S}$ & $4.8 \pm 0.95^{*} \S \S \S$ \\
\hline Nppa & $1.0 \pm 0.29$ & $10 \pm 1.3^{\S \S \S \S}$ & $11 \pm 3.1^{\S \S \S}$ \\
\hline $\mathrm{Nppb}$ & $1.0 \pm 0.22$ & $4.8 \pm 0.31^{\$ \S \S \S}$ & $2.6 \pm 0.42^{* * * \S \S}$ \\
\hline Sod 1 & $1.0 \pm 0.10$ & $1.2 \pm 0.070$ & $1.0 \pm 0.12$ \\
\hline Sod2 & $1.0 \pm 0.10$ & $0.96 \pm 0.078$ & $1.0 \pm 0.079$ \\
\hline Sod3 & $1.0 \pm 0.31$ & $1.7 \pm 0.20$ & $1.6 \pm 0.31$ \\
\hline \multicolumn{4}{|l|}{ Lipid peroxidation } \\
\hline MDA (nmol mg protein ${ }^{-1}$ ) & $2.5 \pm 0.19$ & $2.2 \pm 0.17$ & $2.7 \pm 0.17$ \\
\hline
\end{tabular}

Abbreviations: AdLDLr, adenoviral LDLr; Agtr1a, angiotensin II receptor, type 1a; Ctgf, connective tissue growth factor; Gapdh, glyceraldehyde 3phosphate dehydrogenase; MDA, malondialdehyde; MI, myocardial infarction; Nox, NADPH oxidase; Nppa, natriuretic peptide precursor type A; Nppb, natriuretic peptide precursor type B; LDLr, LDL receptor; LV, left ventricular; qRT-PCR, quantitative reverse transcriptase polymerase chain reaction Sod, superoxide dismutase; TBARS, thiobarbituric acid reactive substances. ${ }^{*} P<0.05,{ }^{* * *} P<0.001$ for comparison of control versus AdLDLr-treated mice. ${ }^{\$ \$} P<0.01,{ }^{\$ \$} \$ p<0.001,{ }^{\$ \$ \$ \$} P<0.0001$ for comparison versus non-infarcted mice. Data are presented as means \pm s.e.m. qRT-PCR analysis ( $n=7-15$ per group) was performed using Taqman gene expression assays. Gene expression data analysis was performed using $\Delta \Delta$ Ct-based fold-change calculations and data are expressed relative to values in non-infarcted control mice. The degree of lipid peroxidation in LV homogenates ( $n=8$ per group) is expressed as MDA equivalents ( $\mathrm{nmol}$ ) per $\mathrm{mg}$ protein using the TBARS assay according to the instructions of the manufacturer (Cayman Chemical).

AdLDLr MI mice (Table 6). Myocardial lipid peroxidation as analyzed by the thiobarbituric acid reactive substances (TBARS) assay were not increased 28 days after $\mathrm{Ml}$ and were similar in control and AdLDLr-treated MI mice (Table 6).
LDLr gene transfer decreases MMP activity in the infarct area of hypercholesterolemic mice 3 days post-MI

Three days after LAD ligation, activities of matrix metalloproteinases (MMP)-2 and MMP-9 were quantified in the myocardial infarct area using gelatin zymography (Figure 7). Pro-MMP-9 levels were $36 \%(P<0.05)$ lower in AdLDLr gene transfer $\mathrm{Ml}$ mice compared with control MI mice (Figure 7a). Active MMP-9 levels were undetectable in day 3 post-MI samples. Pro-MMP-2 and active MMP-2 levels were $35 \%(P=\mathrm{NS})$ and $18 \%(P=\mathrm{NS})$ reduced, respectively, at day 3 in AdLDLr MI mice compared with control MI mice (Figures $7 \mathrm{~b}$ and $\mathrm{c}$ ).

\section{DISCUSSION}

The main findings of this study are that (1) selective cholesterollowering induced by AdLDLr gene transfer in hyperlipidemic C57BL/6 $\mathrm{LDLr}^{-/-}$mice improves survival after $\mathrm{Ml}$ induced by permanent ligation of the LAD; (2) LDLr gene transfer enhances infarct contraction in this model leading to a reduction of infarct size at day 28 compared with control MI mice; (3) selective lipidlowering attenuates after LDLr gene transfer ventricular remodeling as evidenced by decreased cardiomyocyte hypertrophy, reduces interstitial fibrosis and improves myocardial vascularization after $\mathrm{Ml}$; and (4) LV contractility and relaxation are significantly improved 28 days post-MI in AdLDLr-treated mice compared with control $\mathrm{MI}$ mice and improved cardiac function is reflected in a better preservation of aortic systolic and diastolic pressures. Taken together, the current LDLr gene transfer intervention study demonstrates that plasma cholesterol levels have a significant impact on myocardial biology post-Ml.

Till now, no lege artis experimental study has investigated direct effects of hypercholesterolemia on myocardial biology post-MI. Lipid lowering may affect ventricular remodeling post-MI indirectly via enhanced coronary endothelial function and improved coronary perfusion post-MI. Therefore, to exclude these salutary coronary effects of lipid-lowering post-MI, we used a model of permanent ligation of the left anterior descending coronary artery and not a model of ischemia-reperfusion injury. In the setting of ischemia-reperfusion injury, modulation of plasma cholesterol levels by dietary manipulations has been performed in several studies. ${ }^{14-16}$ Higher plasma cholesterol levels were associated with more pronounced infarct inflammation and a larger infarct size in a rat model of type 2 diabetes, ${ }^{14}$ in a rabbit model ${ }^{15}$ and in a porcine model. ${ }^{16}$ However, the dietary manipulations in these studies are complex, ${ }^{14,16}$ and may also induce lipid-loweringindependent effects. Furthermore, plasma cholesterol levels in the rabbit study were astronomically high, ${ }^{15}$ which may undermine the pathophysiological relevance. This study not only differs by the used model of $\mathrm{Ml}$, but also by the absence of any dietary manipulation in the intervention phase. Thus, gene transfer with AdLDLr allowed us to investigate the effect of a selective lipid-lowering intervention.

An important result of this study is that AdLDLr gene transfer in C57BL/6 $\mathrm{LDLr}^{-1-}$ mice significantly decreased mortality after MI compared with control MI mice. Since the timing of mortality coincided with the known time period of ventricular rupture in mice, ${ }^{17}$ reduced mortality may be attributed to a decreased incidence of ventricular rupture. A combination of factors, including an exaggerated inflammatory response and upregulation of MMPs and an impaired reparative fibrotic response, may have a role in the pathogenesis of ventricular rupture. ${ }^{18}$ In this study, MMP activity in the infarct area 3 days post-MI was markedly lower in the AdLDLr MI group than in the control MI group. Inflammatory cell infiltration at day 7 after Ml was more pronounced in the control Ml group compared with the AdLDLr $\mathrm{Ml}$ group, as evidenced by the higher CD45 immunoreactivity in the remote LV myocardium of control MI mice. The interpretation of these results should further take into account the effect of 
a

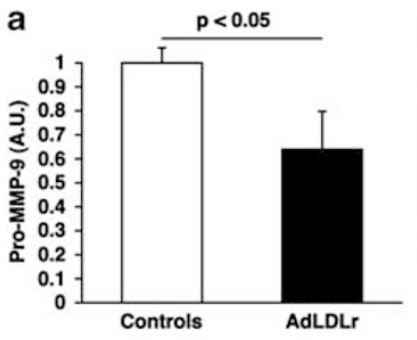

b

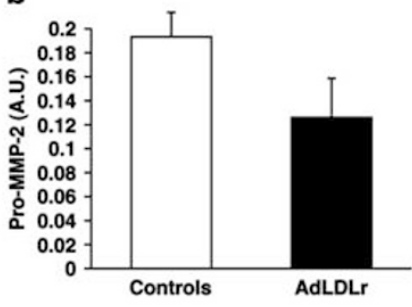

C

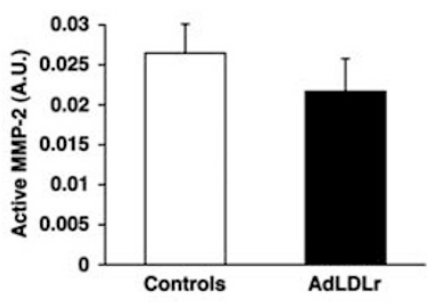

d

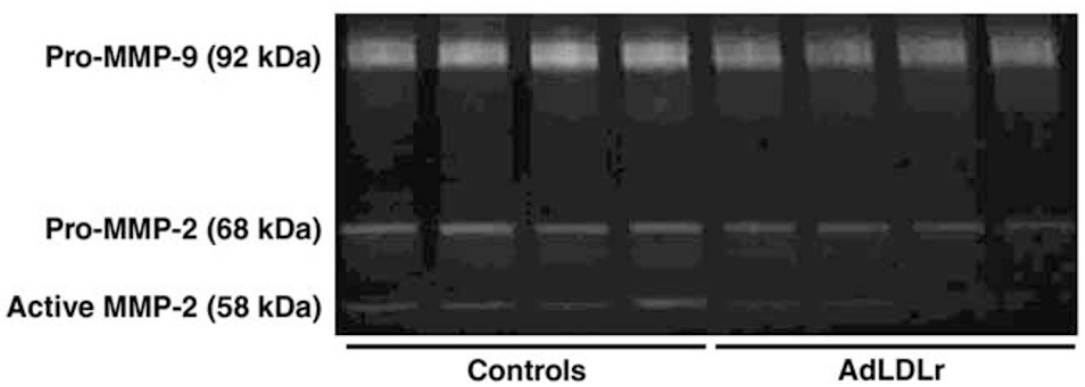

Figure 7. Gelatin zymography demonstrating the activity of MMP-2 and MMP-9 in myocardial infarct tissue isolated from control and AdLDLrtreated female C57BL/6 LDLr ${ }^{-1-}$ mice 3 days after MI. Pro-MMP-9 (a), pro-MMP-2 (b) and active MMP-2 (c) levels are expressed in arbitrary units relative to the pro-MMP-9 value in control female C57BL/6 $\mathrm{LDLr}^{-1-}$ mice. Data are shown as means \pm s.e.m. ( $n=8$ per group). (d) Representative zymogram gel showing gelatinolytic activity in the 3-day-old infarcts of both mice groups. A.U., arbitrary units.

survival bias. Indeed, died mice may represent animals with the highest degree of inflammation and of extracellullar matrix degradation leading to ventricular rupture. The number of myofibroblasts, identified by smooth muscle cell $\alpha$-actin expression, was not affected by AdLDLr gene transfer, which corresponded to an equal deposition of newly formed collagen in the infarct area of both groups. Effective infarct healing is also dependent on the formation of a neovasculature capable to deliver oxygen and nutrients. ${ }^{19,20}$ Lipid lowering significantly increased vascularization 28 days post-Ml in the infarct area and increased relative vascularity in the remote myocardium, which may have contributed to the better preserved cardiac function in AdLDLr-treated MI mice. AdLDLr gene transfer had beneficial effects on EPC number and ex vivo EPC function, but did not increase EPC incorporation at day 28 compared with the control Ml group. Thus, beneficial effects of selective lipid lowering on EPC number and function may have improved neovascularization in a paracrine way by releasing angiogenic factors and proteases to stimulate sprouting of local vessels. ${ }^{21}$ Indeed, it has been shown that myocardial EPC transplantation induces humoral effects, which are sustained by host tissues and have a crucial role in repairing myocardial injury. ${ }^{22}$

A second prominent finding of this study is that infarct size at day 28 was significantly smaller in AdLDLr gene transfer mice compared with control mice, without a significant difference at day 1 and day 7. Increased infarct contraction in the AdLDLr MI group and consequent beneficial effects on the loading conditions of the remote LV myocardium may have contributed significantly to the attenuation of ventricular remodeling. LV remodeling is characterized by LV chamber dilatation, cardiomyocyte hypertrophy and interstitial collagen deposition. ${ }^{23}$ In this study, AdLDLr gene transfer significantly attenuated cardiomyocyte hypertrophy following $\mathrm{MI}$ and increased relative vascularity in the remote LV myocardium. The increase in relative vascularity by lipid-lowering treatment implies an improvement of the balance between the vascular and cardiomyocyte compartment in the myocardium and may result in a better protection against the progression to heart failure. ${ }^{13,24}$ Histological analysis showed a higher level of interstitial myocardial fibrosis in control MI mice compared with AdLDLr MI mice. Correspondingly, Ctgf mRNA expression was higher at day 28 after $\mathrm{Ml}$ in control mice than in AdLDLr mice. Increased collagen deposition in the control MI group may have contributed to the worse LV diastolic function by increased myocardial stiffness. ${ }^{25}$ The more severe remodeling and more compromised LV function in control MI mice than in AdLDLr MI mice was also reflected by higher ventricular mRNA expression of Nppb, known to be specifically induced in severe heart failure. ${ }^{26}$ Lack of difference in the mRNA expression levels of Nppa between both Ml groups may be due to the fact that maximal Nppa mRNA expression is already induced by a slightly impaired ventricular function. ${ }^{26}$ The cardiac reninangiotensin system is highly involved in the remodeling process post-MI. ${ }^{27}$ Expression levels of various renin-angiotensin system components, including angiotensin II receptors, are altered in the cardiac tissue following MI. In our study, LV mRNA expression of Agtr1a was significantly reduced 28 days following Ml. Downregulation of Agtr1 was also observed in post-infarct myocardium of rats $^{28}$ and in end-stage failing human ventricle, ${ }^{29,30}$ and may be the result of chronic stimulation by its agonist, angiotensin $1 .{ }^{31}$ In this study, Agtrla mRNA expression was significantly lower in control MI mice compared with AdLDLr-treated MI mice, suggesting a higher activation of the cardiac renin-angiotensin system in hypercholesterolemic mice leading to a more pronounced downregulation of the angiotensin II receptor type 1 . Another potential modulator of ventricular remodeling post-MI is oxidative stress. ${ }^{32,33}$ Potential cardiac sources of reactive oxygen species include mitochondria, xanthine oxidase, uncoupled NO synthase and Nox. ${ }^{34}$ As hypercholesterolemia is linked to oxidative stress, ${ }^{35}$ we speculated that the beneficial effects of AdLDLr gene transfer on ventricular remodeling would be, at least partly, mediated by reduced oxidative stress. LV mRNA expression of the two Nox isoforms, Nox2 and Nox4, was significantly increased 28 days post-MI. A similar increase in Nox mRNA expression ${ }^{32}$ or activity ${ }^{36,37}$ after MI has been reported by others. In AdLDLr MI mice, Nox4 mRNA expression was markedly lower compared with control MI mice, suggesting that reactive oxygen species production is reduced following lipid lowering. In contrast, myocardial lipid peroxidation was not significantly different in control MI mice and AdLDLr mice compared with non-infarcted mice. This is not explained by a clear alteration of the cellular antioxidant defense system, ${ }^{33,38}$ since mRNA expression of Sods, the first-line defense against reactive oxygen species, was similar in all groups. We cannot exclude that the formation of other oxidation products than aldehydes, as 
assessed by the TBARS assay, was altered by the intervention. Nevertheless, our data do not support the concept that reduced oxidative stress is an important mediator of the favorable effects of lipid lowering.

Reduced infarct size and attenuated remodeling in the AdLDLr MI mice compared with the control MI mice were associated with a significant better hemodynamic status in the former group as evidenced by improved isovolumetric contraction, isovolumetric relaxation and aortic blood pressures. These data highlight the profound functional consequences of selective lipid lowering and should also be interpreted in the perspective of a survival bias. A beneficial effect of fluvastatin on ventricular remodeling and cardiac function after permanent ligation of the LAD has been shown in normocholesterolemic mice, ${ }^{39}$ but this effect is clearly unrelated to lipid lowering.

Our group has previously shown that AdLDLr gene transfer significantly decreases free cholesterol levels in the myocardium of $\mathrm{C} 57 \mathrm{BL} / 6 \mathrm{LDLr}^{-1-}$ mice fed $0.2 \%$ cholesterol and $10 \%$ coconut oil. ${ }^{8}$ Membrane cholesterol may have pleiotropic effects on cardiomyocyte cell biology. An altered cholesterol content of membranes alters the physical properties of a membrane, ${ }^{9}$ results in an increase in the membrane bilayer width, ${ }^{40}$ and may affect the function of pumps, ion channels and enzymes. Cholesterol enrichment may alter membrane caveolae, ${ }^{41}$ thereby inducing changes in cell signaling, transcription, and protein expression. ${ }^{42}$ Altered expression and function of proteins embedded in the sarcolemmal or sarcoplasmic reticulum membrane of cardiomyocytes has been observed in the presence of hypercholesterolemia. ${ }^{11,43}$ Therefore, a lower membrane cholesterol content may have contributed to the observed beneficial effects of lipid lowering following AdLDLr gene transfer.

In conclusion, the current LDLr gene transfer intervention study shows for the first time that plasma cholesterol levels per se are a determinant of survival, infarct size, LV remodeling and cardiac function after permanent ligation of the LAD. Whereas experimental studies in normocholesterolemic mice indicate that statins have beneficial effects on ventricular remodeling independent of lipid lowering, this study unequivocally demonstrates that lipid lowering per se may affect myocardial biology after MI. Thus, this study supports a new paradigm that assigns a much broader role of plasma cholesterol levels to cell biology than in the strict setting of atherosclerosis and vascular biology.

\section{MATERIALS AND METHODS}

Construction of E1E3E4-deleted adenoviral gene transfer vectors for hepatocyte restricted overexpression of the LDLr

The E1E3E4-deleted adenoviral vector contains an $890 \mathrm{bp}$ human $\alpha_{1}$-antitrypsin promoter and two copies of the $160 \mathrm{bp} \alpha_{1}$-microglobulin enhancer ${ }^{44}$ upstream of the $5^{\prime}$ UTR of the human apo A-I gene, the full-length $2.6 \mathrm{~kb} L D L r$ complementary DNA sequence and two copies of the 774-bp human hepatic control region-1. The E1E3E4-deleted control vector Adnull does not contain an expression cassette and has been described before. ${ }^{45}$ Vector production was performed as described previously. ${ }^{45,46}$

\section{Animals}

Female C57BL/6 $\mathrm{LDLr}^{-1-}$ mice, originally purchased from Jackson Laboratories (Bar Harbor, ME, USA), received a hypercholesterolemic diet containing $0.2 \%(\mathrm{w} / \mathrm{w})$ cholesterol and $10 \%(\mathrm{v} / \mathrm{w})$ coconut oil ad libitum starting from the age of 12 weeks. $\beta$-Actin GFP mice, ${ }^{47}$ kindly provided by Dr Nagy (Toronto, Canada), were backcrossed to C57BL/6 background for eight generations and further crossed with $\mathrm{C} 57 \mathrm{BL} / 6 \mathrm{LDLr}^{-/-}$mice to generate homozygous C57BL/6 $\mathrm{LDLr}^{-1} \beta$-actin GFP mice.

All experimental procedures in animals were performed in accordance with protocols approved by the Institutional Animal Care and Research Advisory Committee of the Katholieke Universiteit Leuven.
In vivo gene transfer

Gene transfer in C57BL/6 $\mathrm{LDLr}^{-/-}$mice was performed 3 weeks after start of the hypercholesterolemic diet by tail vein injection of $5 \times 10^{10}$ adenoviral particles of AdLDLr. Control mice were injected with saline or with $5 \times 10^{10}$ adenoviral particles of the control vector Adnull. ${ }^{45}$ As no difference occurred between the Adnull and saline-injected mice with regard to different endpoints, data of both control groups were consistently pooled.

\section{Blood sampling}

Blood was collected by puncture of the retro-orbital plexus. Anticoagulation was performed with 0.1 volume of $4 \%$ trisodium citrate and plasma was immediately isolated by centrifugation at $1100 \mathrm{~g}$ for $10 \mathrm{~min}$ and stored at $-20^{\circ} \mathrm{C}$.

\section{Myocardial infarction}

Two weeks after gene transfer or saline injection, MI was induced in female C57BL/6 $\mathrm{LDLr}^{-1-}$ mice by permanent ligation of the LAD. Mice were anesthetized by intraperitoneal administration of $50-70 \mathrm{mg} \mathrm{kg}^{-1}$ sodium pentobarbital (Nembutal, Ceva, Brussels, Belgium), intubated, and mechanically ventilated (stroke volume in $\mu \mathrm{l}((3 \times$ body weight $(g))+155)$; frequency: 120 strokes per minute; MiniVent Model 845, Hugo-Sachs Elektronik-Harvard Apparatus GmbH, March-Hugstetten, Germany). A left intercostal thoracotomy was performed. Ligation of the LAD was achieved with a 6-0 prolene ligatures about $1 \mathrm{~mm}$ distal from the tip of the left atrium. Successful ligation of the LAD was visualized by immediate discoloration of the myocardium. The thoracic cavity was closed with three 6-0 Ti-Cron sutures. After closure of the skin with 5-0 silksutures, positive pressure was applied at the end of expiration to achieve re-expansion of the lungs. Sham-operated mice underwent the same procedure without occlusion of the LAD.

\section{In vivo hemodynamic measurements}

Invasive hemodynamic measurements were performed 28 days after $\mathrm{MI}$ or sham operation. Mice were anesthetized by intraperitoneal administration of $1.4 \mathrm{~g} \mathrm{~kg}^{-1}$ urethane (Sigma, Steinheim, Germany). Body temperature was maintained with a heating pad and monitored with a rectal probe. An incision in the right carotid artery was made with a 26-gauge needle between a distal and proximal non-occlusive ligation of the artery. A 1.4 French Millar pressure catheter (SPR-67/NR; Millar Instruments, Houston, TX, USA) was inserted and advanced to the left ventricle (LV). After stabilization of the catheter, heart rate, maximal systolic LV pressure, minimal diastolic LV pressure, the peak rate of isovolumetric LV contraction $\left(\mathrm{dP} / \mathrm{dt}_{\max }\right)$ and the peak rate of isovolumetric $\mathrm{LV}$ relaxation $\left(\mathrm{dP} / \mathrm{dt}_{\text {min }}\right)$ were measured. The end-diastolic LV pressure was calculated manually from the pressure in function of time curves. The time constant of isovolumetric LV pressure fall (tau) was calculated using the method of Weiss et al. ${ }^{48}$ Arterial blood pressure measurements were obtained after withdrawal of the catheter from the LV to the ascending aorta. Data were registered with Powerlab Bridge Amplifier and Chart Software (sampling rate $2000 \mathrm{~Hz}$; Fysicon, Oss, The Netherlands).

\section{Bone marrow transplantations}

Please see the Supplementary Results in the online-only Supplement.

\section{Plasma lipid analysis}

Mouse lipoproteins were separated by density gradient ultracentrifugation in a swing-out rotor as described before. ${ }^{8}$ Fractions were stored at $-20^{\circ} \mathrm{C}$ until analysis. Total cholesterol in plasma and lipoprotein fractions was determined with commercially available enzymes (Roche Diagnostics, Basel, Switzerland). Precipath L (Roche Diagnostics) was used as a standard.

\section{Quantitative reverse transcriptase polymerase chain reaction} analysis

Twenty-eight days after MI, hearts were dissected, briefly rinsed with saline buffer, snap-frozen and stored at $-80^{\circ} \mathrm{C}$ until use. RNA was extracted from 
non-infarcted LV myocardium using TRIzol reagent (Invitrogen, Carlsbad, CA, USA) and the Purelink RNA Mini Kit (Invitrogen). An on-column DNase treatment was performed using Purelink DNase (Invitrogen) according to the manufacturer's protocol. Total RNA $(1 \mu \mathrm{g})$ was reverse transcribed using the QuantiTect Reverse Transcription kit (Qiagen, Hamburg, Germany). Quantitative reverse transcriptase polymerase chain reaction was performed on a 7500 FAST real-time PCR system (Applied Biosystems, Carlsbad, CA, USA) using the TaqMan Fast Universal PCR Master Mix (Applied Biosystems) and a premade mix containing primers and MGB probes (Taqman gene expression assay, Applied Biosystems; see Supplementary Table 1 for details) to quantify Agtr1a, Ctgf, Nox2, Nox4, Nppa, Nppb, Sod1, Sod 2 and Sod3 complementary DNA levels $(n=7-15$ per group). The glyceraldehyde 3-phosphate dehydrogenase housekeeping gene was used as endogenous control. Data analysis was performed using $\Delta \Delta$ Ct-based fold-change calculations.

\section{Gelatin zymography}

Please see the Supplementary Results in the online-only Supplement.

\section{Evaluation of lipid peroxidation in heart tissue by TBARS assay} LV samples isolated from the non-infarcted LV myocardium were homogenized in RIPA lysis buffer supplemented with Complete proteinase inhibitor (Roche Diagnostics) and phosphatase inhibitor $(1 \times$ PhosSTOP, Roche Diagnostics) in a volume of $10 \mu \mathrm{l}$ buffer $\mathrm{mg}^{-1}$ tissue, as described above. Following the execution of the TBARS assay according to the instructions of the manufacturer (Cayman Chemical, Ann Arbor, MI, USA), the degree of lipid peroxidation in LV homogenates ( $n=8$ per group) was expressed as malondialdehyde equivalents.

\section{Murine spleen EPC culture assay}

Please see the Supplementary Results in the online-only Supplement. ${ }^{49}$

\section{EPC migration assay}

Please see the Supplementary Results in the online-only Supplement. ${ }^{49}$

\section{EPC adhesion assay}

Please see the Supplementary Results in the online-only Supplement. ${ }^{49}$

\section{Area at risk and infarct size assessment 1 day after MI}

Please see the Supplementary Results in the online-only Supplement.

\section{Tissue preparation for histological analysis}

At 7 or 28 days after MI, hearts were harvested for histological analysis. Mice were perfused via the abdominal aorta with phosphate-buffered saline and hearts were arrested in diastole by $\mathrm{CdCl}(100 \mu \mathrm{l} ; 0.1 \mathrm{~N})$, followed by perfusion fixation with $1 \%$ paraformaldehyde in phosphate-buffered saline. After dissection, hearts were post-fixated overnight in $1 \%$ paraformaldehyde, embedded in paraffin and $6 \mu \mathrm{m}$ thick cross-sections at $130 \mu \mathrm{m}$ spaced intervals were made extending from the apex to the basal part of the LV.

\section{Morphometric analysis of LV remodeling}

LV remodeling was assessed by morphometric analysis on mosaic images of Sirius red-stained heart cross-sections using Axiovision 4.6 software (Zeiss, Zaventem, Belgium). Infarct size (\%) at day 7 and day 28 post-MI was calculated according to Takagawa et $a .^{50}$ by dividing the sum of midline infarct lengths from all sections by the sum of midline LV circumferences from all sections and multiplying by 100 . Midline infarct length was defined as the midline length of infarct that included $>50 \%$ of the whole thickness of the myocardial wall. Whole LV area $\left(\mu \mathrm{m}^{2}\right), \mathrm{LV}$ cavity area $\left(\mu \mathrm{m}^{2}\right)$, LV remote muscle area $\left(\mu \mathrm{m}^{2}\right.$; including the septum) and infarct area $\left(\mu \mathrm{m}^{2}\right)$ were analyzed. Infarct wall thickness $(\mu \mathrm{m})$ was measured at equidistant points over the infarct area perpendicular to the infarcted wall. The thinning index was determined as the ratio of the mean infarct wall thickness normalized to the mean septal wall thickness. Expansion index was calculated as ((mean septal thickness/mean infarct thickness) $\times$ (LV cavity area/whole LV area)). ${ }^{51}$ All geometric measurements were computed in a blinded fashion from representative tissue sections of four separate regions and the average value was used to represent that animal for statistical purposes.

To assess the degree of fibrosis in the heart, the area of collagen deposition was traced on Sirius red-stained tissue sections using polarized light and spectral thresholding allowing evaluation of tightly packed (redorange) type I collagen versus thin, loosely assembled (yellow-green) type III collagen on a Leica RBE microscope with KS300 software (Zeiss). The degree of intersitital fibrosis (\%) and the degree of collagen deposition in the infarct area (\%) is expressed as the total collagen-positive area normalized to the total LV remote area or infarct area, respectively. Any perivascular fibrosis was excluded from this analysis. Two mid-ventricular sections were studied per animal.

Cardiomyocyte hypertrophy was analyzed on laminin-stained sections by measuring the cardiomyocyte cross-sectional area $\left(\mu \mathrm{m}^{2}\right)$ of at least 200 randomly selected cardiomyocytes in the non-infarcted LV myocardium. Two mid-ventricular cross-sections were analyzed per mouse. Cardiomyocyte density was determined on the same laminin-stained sections by counting the number of cross-sectioned round shaped cardiomyocytes per $\mathrm{mm}^{2}$ of cardiomyocyte-covered LV myocardium.

\section{Immunohistochemistry}

Paraffin sections were stained with rat anti-mouse CD45 (BD Biosciences, San Jose, CA, USA; 1/100) to detect leukocytes. Inflammatory cells were quantified in a blinded fashion by computer-assisted image analysis using KS300 software (Zeiss). Myofibroblast infiltration was examined as the percentual area of the infarct positively stained for mouse anti-human smooth muscle cell $\alpha$-actin (Dako, Glostrup, Denmark; $1 / 500$ ), excluding coronary vessels. Capillary density in the infarct area, the infarct border zone, and the non-infarcted myocardium was determined on sections stained with rat anti-mouse CD31 antibodies (BD Biosciences; 1/500). Relative vascularity in the non-infarcted myocardium was determined as ((capillary density (number $\mathrm{mm}^{-2}$ )/cardiomyocyte density (number $\left.\mathrm{mm}^{-2}\right)$ )/ cardiomyocyte cross-sectional area $\left.\left(\mu \mathrm{m}^{2}\right)\right)^{13}$ and was assessed on sections double stained for rat anti-mouse CD31 (BD Biosciences; 1/500) and rabbit anti-mouse laminin (Sigma; 1/50). To evaluate EPC incorporation in the infarct area and infarct border zone, heart sections from bone marrow transplantation mice were immunohistochemically double stained with rabbit anti-mouse GFP (Molecular Probes, Carlsbad, CA, USA; 1/200) and rat anti-mouse CD31 (BD Biosciences; 1/500) antibodies. Nuclei were visualized with 4,6-diamidino-2-phenylindole (DAPI) (Invitrogen). Only GFP CD31 double-positive cells that colocalized with a DAPI signal were considered as bone marrow-derived endothelial cells. Data are expressed as the number of $\mathrm{GFP}^{+} \mathrm{CD} 31^{+}$capillaries per $\mathrm{mm}^{2}$ of cross-sectional area.

\section{Statistical analysis}

All data are expressed as means \pm s.e.m. Areas under the curve were calculated using Prism4 (GraphPad Software, San Diego, CA, USA). Parameters were generally compared between two groups with an unpaired Student's $t$-test using Instat3 (GraphPad Software). When indicated, a logarithmic transformation, a square root transformation, or a non-parametric Mann-Whitney test was performed. Kaplan-Meier survival curves were analyzed by log-rank test using Prism4 (GraphPad Software). A two-sided $P$-value of $<0.05$ was considered statistically significant.

\section{CONFLICT OF INTEREST}

The authors declare no conflict of interest.

\section{ACKNOWLEDGEMENTS}

This work was supported by Grants G.0533.08 and G.0599.09N of the Fonds voor Wetenschappelijk Onderzoek-Vlaanderen. The Center for Molecular and Vascular 
Biology is supported by the Excellentiefinanciering KU Leuven (EF/05/013). Eline Van Craeyveld is a Research Assistant of the Fonds voor Wetenschappelijk OnderzoekVlaanderen. Frank Jacobs is a postdoctoral fellow of the Fonds voor Wetenschappelijk Onderzoek-Vlaanderen. Stephanie C Gordts is a Research Assistant of the Agentschap voor Innovatie door Wetenschap en Technologie (IWT).

\section{REFERENCES}

1 Sutton MG, Sharpe N. Left ventricular remodeling after myocardial infarction: pathophysiology and therapy. Circulation 2000; 101: 2981-2988.

2 He J, Ogden LG, Bazzano LA, Vupputuri S, Loria C, Whelton PK. Risk factors for congestive heart failure in US men and women: NHANES I epidemiologic followup study. Arch Intern Med 2001; 161: 996-1002.

3 Wang TD, Wu CC, Chen WJ, Lee CM, Chen MF, Liau CS et al. Dyslipidemias have a detrimental effect on left ventricular systolic function in patients with a first acute myocardial infarction. Am J Cardiol 1998; 81: 531-537.

4 Aronow HD, Lincoff AM, Quinn MJ, McRae AT, Gurm HS, Houghtaling PL et al. Relation between previous lipid-lowering therapy and infarct size (creatine kinase-MB level) in patients presenting with acute myocardial infarction. Am J Cardiol 2008; 102: 1119-1124.

5 Hoffmann R, Haager P, Suliman H, Christott P, Radke P, Blindt R et al. Effect of statin therapy before Q-wave myocardial infarction on myocardial perfusion. Am J Cardiol 2008; 101: 139-143.

6 Jones SP, Gibson MF, Rimmer 3rd DM, Gibson TM, Sharp BR, Lefer DJ. Direct vascular and cardioprotective effects of rosuvastatin, a new HMG-CoA reductase inhibitor. J Am Coll Cardiol 2002; 40: 1172-1178.

7 Wolfrum S, Dendorfer A, Schutt M, Weidtmann B, Heep A, Tempel K et al. Simvastatin acutely reduces myocardial reperfusion injury in vivo by activating the phosphatidylinositide 3-kinase/Akt pathway. J Cardiovasc Pharmacol 2004; 44 348-355.

8 Jacobs F, Van Craeyveld E, Feng Y, Snoeys J, De Geest B. Adenoviral low density lipoprotein receptor attenuates progression of atherosclerosis and decreases tissue cholesterol levels in a murine model of familial hypercholesterolemia. Atherosclerosis 2008; 201: 289-297.

9 Yeagle PL. Cholesterol and the cell membrane. Biochim Biophys Acta 1985; 822: 267-287.

10 Huang Y, Walker KE, Hanley F, Narula J, Houser SR, Tulenko TN. Cardiac systolic and diastolic dysfunction after a cholesterol-rich diet. Circulation 2004; 109: 97102.

11 Luo TY, Su MJ, Yang YF, Liu YB, Liang HC, Wu CC et al. Effect of hypercholesterolemia on myocardial function in New Zealand white rabbits. J Biomed Sci 2004; 11: 829-837.

12 Bastiaanse EM, Atsma DE, Kuijpers MM, Van der Laarse A. The effect of sarcolemmal cholesterol content on intracellular calcium ion concentration in cultured cardiomyocytes. Arch Biochem Biophys 1994; 313: 58-63.

13 Shimizu I, Minamino T, Toko H, Okada S, Ikeda H, Yasuda N et al. Excessive cardiac insulin signaling exacerbates systolic dysfunction induced by pressure overload in rodents. J Clin Invest 2010; 120: 1506-1514.

14 Hoshida S, Yamashita N, Otsu K, Kuzuya T, Hori M. Cholesterol feeding exacerbates myocardial injury in Zucker diabetic fatty rats. Am J Physiol Heart Circ Physiol 2000; 278: H256-H262.

15 Hoshida S, Nishida M, Yamashita N, Igarashi J, Hori M, Kamada $T$ et al. Amelioration of severity of myocardial injury by a nitric oxide donor in rabbits fed a cholesterol-rich diet. J Am Coll Cardiol 1996; 27: 902-909.

16 Osipov RM, Bianchi C, Feng J, Clements RT, Liu Y, Robich MP et al. Effect of hypercholesterolemia on myocardial necrosis and apoptosis in the setting of ischemia-reperfusion. Circulation 2009; 120: S22-S30.

17 Gao XM, Xu Q, Kiriazis H, Dart AM, Du XJ. Mouse model of post-infarct ventricular rupture: time course, strain- and gender-dependency, tensile strength, and histopathology. Cardiovasc Res 2005; 65: 469-477.

18 Wang F, Keimig T, He Q, Ding J, Zhang Z, Pourabdollah-Nejad S et al. Augmented healing process in female mice with acute myocardial infarction. Gend Med 2007; 4: $230-247$.

19 Wang B, Ansari R, Sun Y, Postlethwaite AE, Weber KT, Kiani MF. The scar neovasculature after myocardial infarction in rats. Am J Physiol Heart Circ Physiol 2005; 289: H108-H113.

20 Virag Jl, Murry CE. Myofibroblast and endothelial cell proliferation during murine myocardial infarct repair. Am J Pathol 2003; 163: 2433-2440.

21 Rehman J, Li J, Orschell CM, March KL. Peripheral blood 'endothelial progenitor cells' are derived from monocyte/macrophages and secrete angiogenic growth factors. Circulation 2003; 107: 1164-1169.

22 Cho HJ, Lee N, Lee JY, Choi YJ II M, Wecker A et al. Role of host tissues for sustained humoral effects after endothelial progenitor cell transplantation into the ischemic heart. J Exp Med 2007; 204: 3257-3269.
23 Pfeffer MA, Braunwald E. Ventricular remodeling after myocardial infarction. Experimental observations and clinical implications. Circulation 1990; 81: $1161-1172$

24 Tirziu D, Chorianopoulos E, Moodie KL, Palac RT, Zhuang ZW, Tjwa M et al. Myocardial hypertrophy in the absence of external stimuli is induced by angiogenesis in mice. J Clin Invest 2007; 117: 3188-3197.

25 van den Borne SW, Isobe S, Verjans JW, Petrov A, Lovhaug D, Li P et al. Molecular imaging of interstitial alterations in remodeling myocardium after myocardial infarction. J Am Coll Cardiol 2008; 52: 2017-2028.

26 Langenickel T, Pagel I, Hohnel K, Dietz R, Willenbrock R. Differential regulation of cardiac ANP and BNP mRNA in different stages of experimental heart failure. Am J Physiol 2000; 278: H1500-H1506.

27 Sun Y. Intracardiac renin-angiotensin system and myocardial repair/remodeling following infarction. J Mol Cell Cardiol 2010: 483-489.

28 Lax CJ, Domenighetti AA, Pavia JM, Di Nicolantonio R, Curl CL, Morris MJ et al. Transitory reduction in angiotensin AT2 receptor expression levels in postinfarct remodelling in rat myocardium. Clin Exp Pharmacol Physiol 2004; 31: 512-517.

29 Haywood GA, Gullestad L, Katsuya T, Hutchinson HG, Pratt RE, Horiuchi M et al. AT1 and AT2 angiotensin receptor gene expression in human heart failure. Circulation 1997; 95: 1201-1206.

30 Asano K, Dutcher DL, Port JD, Minobe WA, Tremmel KD, Roden RL et al. Selective downregulation of the angiotensin II AT1-receptor subtype in failing human ventricular myocardium. Circulation 1997; 95: 1193-1200.

31 Lassegue B, Alexander RW, Nickenig G, Clark M, Murphy TJ, Griendling KK. Angiotensin II down-regulates the vascular smooth muscle AT1 receptor by transcriptional and post-transcriptional mechanisms: evidence for homologous and heterologous regulation. Mol Pharmacol 1995; 48: 601-609.

32 Looi YH, Grieve DJ, Siva A, Walker SJ, Anilkumar N, Cave AC et al. Involvement of Nox2 NADPH oxidase in adverse cardiac remodeling after myocardial infarction. Hypertension 2008; 51: 319-325.

33 Hill MF, Singal PK. Antioxidant and oxidative stress changes during heart failure subsequent to myocardial infarction in rats. Am J Pathol 1996; 148: 291-300.

34 Sorescu D, Griendling KK. Reactive oxygen species, mitochondria, and NAD(P)H oxidases in the development and progression of heart failure. Congest Heart Fail 2002; 8: 132-140.

35 Oliveira HC, Cosso RG, Alberici LC, Maciel EN, Salerno AG, Dorighello GG et al. Oxidative stress in atherosclerosis-prone mouse is due to low antioxidant capacity of mitochondria. FASEB J 2005; 19: 278-280.

36 Doerries C, Grote K, Hilfiker-Kleiner D, Luchtefeld M, Schaefer A, Holland SM et al Critical role of the $\mathrm{NAD}(\mathrm{P}) \mathrm{H}$ oxidase subunit p47phox for left ventricular remodeling/dysfunction and survival after myocardial infarction. Circ Res 2007; 100: 894-903.

37 Qin F, Simeone $\mathrm{M}$, Patel R. Inhibition of $\mathrm{NADPH}$ oxidase reduces myocardial oxidative stress and apoptosis and improves cardiac function in heart failure after myocardial infarction. Free Radic Biol Med 2007; 43: 271-281.

38 van Deel ED, Lu Z, Xu X, Zhu G, Hu X, Oury TD et al. Extracellular superoxide dismutase protects the heart against oxidative stress and hypertrophy after myocardial infarction. Free Radic Biol Med 2008; 44: 1305-1313.

39 Hayashidani S, Tsutsui H, Shiomi T, Suematsu N, Kinugawa S, Ide T et al. Fluvastatin, a 3-hydroxy-3-methylglutaryl coenzyme a reductase inhibitor, attenuates left ventricular remodeling and failure after experimental myocardial infarction. Circulation 2002; 105: 868-873.

40 Tulenko TN, Chen M, Mason PE, Mason RP. Physical effects of cholesterol on arterial smooth muscle membranes: evidence of immiscible cholesterol domains and alterations in bilayer width during atherogenesis. J Lipid Res 1998; 39: 947-956.

41 Zhu Y, Liao HL, Wang N, Yuan Y, Ma KS, Verna L et al. Lipoprotein promotes caveolin-1 and Ras translocation to caveolae: role of cholesterol in endothelial signaling. Arterioscler Thromb Vasc Biol 2000; 20: 2465-2470.

42 Okamoto T, Schlegel A, Scherer PE, Lisanti MP. Caveolins, a family of scaffolding proteins for organizing 'preassembled signaling complexes' at the plasma membrane. J Biol Chem 1998; 273: 5419-5422.

43 Kutryk MJ, Pierce GN. Stimulation of sodium-calcium exchange by cholesterol incorporation into isolated cardiac sarcolemmal vesicles. J Biol Chem 1988; 263: 13167-13172.

44 Jacobs F, Snoeys J, Feng Y, Van Craeyveld E, Lievens J, Armentano D et al. Direct comparison of hepatocyte-specific expression cassettes following adenoviral and nonviral hydrodynamic gene transfer. Gene Therapy 2008; 15: 594-603.

45 Van Linthout S, Lusky M, Collen D, De Geest B. Persistent hepatic expression of human apo A-I after transfer with a helper-virus independent adenoviral vector. Gene Therapy 2002; 9: 1520-1528.

46 Van Craeyveld E, Gordts SC, Nefyodova E, Jacobs F, De Geest B. Regression and stabilization of advanced murine atherosclerotic lesions: a comparison of LDL lowering and HDL raising gene transfer strategies. J Mol Med 2011; 89: 555-567. 
47 Hadjantonakis AK, Gertsenstein M, Ikawa M, Okabe M, Nagy A. Generating green fluorescent mice by germline transmission of green fluorescent ES cells. Mech Dev 1998; 76: 79-90.

48 Weiss JL, Frederiksen JW, Weisfeldt ML. Hemodynamic determinants of the time-course of fall in canine left ventricular pressure. J Clin Invest 1976; 58: 751-760.

49 Feng $Y$, Jacobs F, Van Craeyveld E, Brunaud C, Snoeys J, Tjwa M et al. Human ApoA-I transfer attenuates transplant arteriosclerosis via enhanced incorporation of bone marrow-derived endothelial progenitor cells. Arterioscler Thromb Vasc Biol 2008; 28: 278-283.
50 Takagawa J, Zhang Y, Wong ML, Sievers RE, Kapasi NK, Wang Y et al. Myocardial infarct size measurement in the mouse chronic infarction model: comparison of area- and length-based approaches. J Appl Physiol 2007; 102: 2104-2111.

51 Virag JA, Rolle ML, Reece J, Hardouin S, Feigl EO, Murry CE. Fibroblast growth factor-2 regulates myocardial infarct repair: effects on cell proliferation, scar contraction, and ventricular function. Am J Pathol 2007; 171: 1431-1440.

(c) This work is licensed under the Creative Commons AttributionSOMERIGHSTRESERVED NonCommercial-No Derivative Works 3.0 Unported License. To view a copy of this license, visit http://creativecommons.org/licenses/by-nc-nd/3.0/

Supplementary Information accompanies the paper on Gene Therapy website (http://www.nature.com/gt) 